\title{
Peer Pressure and Smoking Behavior in Elementary School Students
}

\author{
Sinthura Vimalan Subramaniam, ${ }^{1}$ Arifah Nur Istiqomah, ${ }^{2}$ Eddy Fadlyana ${ }^{3}$ \\ ${ }^{1}$ Faculty of Medicine Universitas Padjadjaran, ${ }^{2}$ Department of Psychiatry Faculty of Medicine \\ Universitas Padjadjaran/Dr. Hasan Sadikin General Hospital Bandung, ${ }^{3}$ Department of Child \\ Health Faculty of Medicine Universitas Padjadjaran/Dr. Hasan Sadikin General Hospital Bandung
}

\section{Abstract}

Background:Adolescence is an important period in which many individuals are vulnerable to onset and progression of smoking. Peers are strongly associated with adolescent smoking initiation. This study is conducted to determine whether there is a relationship between peer pressure and smoking behavior in male elementary school students.

Methods: A cross-sectional study was conducted in October 2014. Respondents were male students from grade four and five from state elementary schools (SDN) in Jatinangor district who voluntarily followed the research procedure. The sampling method used in this study was two-stage cluster sampling. A validated questionnaire was provided after getting informed consent from the respondents. The data analysis was performed using chi-square test.

Results: As much as 110 male subjects were included in the study. Data showed that 57 students (51.8\%) which were more than half of the number of students ever smoked and 53 students never smoked. Out of 110 students, 69 students (62.7 \%) experienced peer pressure and 41 students $(37.3 \%)$ never experienced peer pressure. The result of chi-square test from the study showed that the p-value is 0.000 .

Conclusions: There is a relationship between peer pressure and smoking behavior in male elementary school students in Jatinangor district. [AMJ.2017;4(1):1-5]

Keywords: Male elementary school students, peer pressure, smoking behavior

\section{Introduction}

Cigarette smoking still remains as the most vital preventable cause of death. ${ }^{1}$ According to the World Health Organization (WHO), Indonesia is the third largest country in the world in addition to China and India for number of smokers which reached about $146,860,000$ people. ${ }^{2}$

Commonly, people start smoking during adolescence and early age of smoking initiation is associated with more severe outcome later in life.3 In Indonesia the age of start smoking is getting younger day by day. ${ }^{2}$

Peers and family are identified as important factors for initiation of tobacco use as well as for its continuation and progressive use later on. ${ }^{4}$ Based on a survey which studies both peer and parents factors, peers have a greater influence than parents on adolescent smoking. ${ }^{5}$ A study conducted in Nigeria ${ }^{6}$ on tobacco use in school students has discovered that the use of tobacco among youth is greatly influenced by peer pressure. ${ }^{6}$ In Indonesia the age of start smoking is getting younger and prevalence of smoking among children reached the alarming rate. ${ }^{2}$ Out of 70 million children in Indonesia, 25.9 million (37\%) of children smoke tobacco. ${ }^{2}$ Previous data from a national study in Indonesia shows that the smoking behavior is dominant in male compared to female in adolescent more than ten years old. ${ }^{2}$

The objectives of this study was to analyze the relationship between peer pressure and smoking behavior in male elementary school students.

Correspondence: Sinthura Vimalan Subramaniam, Faculty of Medicine, Universitas Padjadjaran, Jalan Raya BandungSumedang Km.21, Jatinangor, Sumedang, Indonesia, Phone: +6287822281194 Email: sinthuravimalan@gmail.com 


\section{Methods}

A cross-sectional study was conducted in October 2014 in elementary schools in Jatinangor district. Data was collected from grade four and five male students from several elementary schools in Jatinangor district. The study was conducted after getting clearance from the ethical committee. A validated and reliable questionnaire was provided to students after getting permission from the head of the schools. The sampling method used in this study was the two-stage cluster sampling. In the first stage, three elementary schools were randomly selected which were SDN Neglasari, SDN Sayang and SDN Cibeusi. In the second stage, a number of grade four and five students of those three particulars schools were selected according to the simple stratified random sampling. A total of 122 respondents were given questionnaires with their consent. The subjects of the study were included if they were male students from grade four and five and voluntarily followed the study procedure. The subjects were excluded from the study if they incompletely and incorrectly filled in the questionnaire. Students were told to answer all the questions provided in the questionnaire. In order to make sure that the students answered the questions correctly, they were told to always ask to clear their doubt regarding the items in the questionnaire. This could make them understand and fill in the questionnaire correctly.

The main purpose of giving a questionnaire was to access students' smoking behavior and to determine whether they experienced peer pressure in their daily life. The questionnaire was created in such a way that it was easily understood by students. The questionnaire was constructed based on modification of a questionnaire from a similar previous study and students were required to choose the best answer from the options provided. First, before conducting the study the student's grade was identified. Informed consent was given to the students regarding the objective of the study and their willingness to participate in the study, then students have to fill in the questionnaire on their own. Peer pressure was evaluated based on the influence exerted by a peer group or an individual encouraging other individuals to smoke. There were six questions in the questionnaire to access both direct and indirect peer pressure and students have to answer 'yes' or 'no' to the questions provided. For direct peer pressure three questions were provided such as "whether any of their peers offer cigarette to them", "whether their peers ask to smoke with them" and "whether their peers force them to smoke". For accessing indirect peer pressure, three questions also asked such as "whether he feels being avoided by his peers if he does not smoke", "whether he feels the need to show-off to his peers that he smokes" and "whether he finds his peers 'cool' if they smoke". Students were considered to have experienced peer pressure if they answered 'yes' to any of these six questions provided in the questionnaire. They were considered to have never experienced peer pressure if they answered 'no' to all the six questions. In order to access smoking behavior of the students, one question was asked to which students had to answer 'yes' or 'no'.. Students were considered ever smoked if they answered 'yes' and considered never smoked if they answered 'no' to this question.

The questionnaire was initially given to 122 students from three schools previously selected for this study who met the inclusion criteria. From the previously selected 122 students, only 110 students were included in the study. Twelve students were excluded because they incompletely and incorrectly filled in the questionnaire.

Furthermore, the univariate and bivariate analysis were included to analyze data in this study. Univariate analysis was used to describe the characteristics of students, number of students who experienced and never experienced peer pressure, and smoking behavior of students whether they ever or never smoked. Univariate data was presented in the form of frequency distribution tables. Moreover, bivariate analysis was used to examine whether there was a relationship between peer pressure and smoking behavior in male elementary school students. The Chisquare test was performed using computer and a statistically significant result was considered when $\mathrm{p}<0.05$.

\section{Results}

More than half of the number of students were from grade five $(53.6 \%)$. The majority of students who participated in this study were with age of $11(47.3 \%)$ and followed by age of ten (Table 1).

Out of 110 students who were included in this study, 57 students (51.8\%) ever smoked. This study also showed that 69 students $(62.7$ $\%$ ) from the total of students experienced peer pressure (Table 2).

Data showed that 76 students (69.09\%) 
Table 1 Characteristics of Students

\begin{tabular}{ccc}
\hline Characteristics of Respondents & Frequency $(\mathbf{n = 1 1 0})$ & Percentage $\%$ \\
\hline Grade & 51 & 46.4 \\
4 & 59 & 53.6 \\
5 & & \\
Age & 3 & 2.7 \\
9 & 48 & 43.6 \\
10 & 52 & 47.3 \\
11 & 7 & 6.4 \\
\hline
\end{tabular}

Table 2 Frequency and Percentage of Smoking Behavior of Students and Students Who Experienced and Never Experienced Peer Pressure

\begin{tabular}{lcc}
\hline \multicolumn{1}{c}{ Variables } & Frequency $(\mathbf{n = 1 1 0})$ & Percentage (\%) \\
\hline Smoking behavior & & \\
Ever smoked & 57 & 51.8 \\
Never smoked & 53 & 48.2 \\
Peer Pressure & & \\
Experienced & 69 & 62.7 \\
Never experienced & 41 & 37.3 \\
\hline
\end{tabular}

from the total of students had smoking peer and the remaining $30.91 \%$ of them did not have smoking peer. Most students experienced direct peer pressure in the form of cigarettes offered by peer (44.55 \%), followed by students who were asked by peer to smoke with them $(43.64 \%)$. Indirect peer pressure in the form of the need to 'show-off' to peer that they smoked was reported as the least form of peer pressure experienced by students with only 11 students (Table 3 ).

The majority of students who experienced peer pressure reported as ever smoked $(81.2 \%)$. Out of 41 students who never experienced peer pressure, 40 students (97.6 $\%)$ never smoked (Table 4).

Chi-square test was performed to find whether there was a relationship between peer pressure and smoking behavior. The result of the test showed that the $p$ value was 0.000 .

\section{Discussion}

A total of 57 students ( $51.8 \%$ ) which was more than half of the number of students reported as ever smoked. Based on 69 students who experienced peer pressure, 56 of them $(81.2 \%)$ ever smoked. Forty students (97.6\%) out of 41 students who never experienced peer pressure reported as never smoked. The percentage of ever smoking students in male elementary school students in Jatinangor district was high if compared with a study conducted by Huang et al. ${ }^{7}$ in southern Taiwan. The study conducted by Huang et al. ${ }^{7}$ shows that the percentage of ever smokers in elementary school students is $13.7 \%$ in which $9.23 \%$ of them are male and $4.47 \%$ are female. From the total of 1,213 male students who participated in the study, 217 students (17.9\%) are ever smokers and 996 students $(82.1 \%)$ are never smokers.

Based on this study it can be concluded that there is a relationship between peer pressure and smoking behavior in adolescent. A study by San San et al. ${ }^{8}$ on risky behavior and associated factors among medical students and community youth in Myanmar shows the rate of smoking in community youth in Myanmar is $28.8 \%$. The study by San San et al. ${ }^{8}$ shows that the presence of friends who are smokers as well 
Table 3 Indicators of Peer Pressure

\begin{tabular}{|c|c|c|c|c|c|c|}
\hline \multirow{2}{*}{$\begin{array}{c}\text { Indicators of peer } \\
\text { pressure }\end{array}$} & \multicolumn{2}{|c|}{ Yes } & \multicolumn{2}{|c|}{ No } & \multicolumn{2}{|c|}{ Total } \\
\hline & Frequency & $\%$ & Frequency & $\%$ & Frequency & $\%$ \\
\hline Smoking peer & 76 & 69.09 & 34 & 30.91 & 110 & 100.0 \\
\hline Peers offer cigarette & 49 & 44.55 & 61 & 55.45 & 110 & 100.0 \\
\hline $\begin{array}{l}\text { Peers ask to smoke with } \\
\text { them }\end{array}$ & 48 & 43.64 & 62 & 56.36 & 110 & 100.0 \\
\hline Peers force to smoke & 34 & 30.91 & 76 & 69.09 & 110 & 100.0 \\
\hline $\begin{array}{l}\text { Feeling of being avoided } \\
\text { by peers if don't smoke }\end{array}$ & 35 & 31.82 & 75 & 68.18 & 110 & 100.0 \\
\hline $\begin{array}{l}\text { Feel the need to show-off } \\
\text { to peers that they smoke }\end{array}$ & 11 & 10.00 & 99 & 90.00 & 110 & 100.0 \\
\hline $\begin{array}{l}\text { Feel that their peers are } \\
\text { 'cool' if they smoke }\end{array}$ & 17 & 15.45 & 93 & 84.55 & 110 & 100.0 \\
\hline
\end{tabular}

as peer pressure are significant contributor factors for smoking. This is a cross-sectional study which includes respondents aged 15 to 24 years. A self-administered questionnaire is used as the method for data collection in this study.

Another study by Jeganthan et al. ${ }^{9}$ on smoking stage relation to peer, school and parental factor in secondary school students in Malaysia shows that $19.3 \%$ are susceptible never smokers, $5.5 \%$ are current smokers, $6 \%$ are experimenters and $3.1 \%$ are exsmokers. This study also indicates that high peer pressure to smoke and having a best friend as smoker increases the odd of being a susceptible never smoker and ever smoker. High peer pressure to smoke proves to have the strongest effect on current smokers in this study. This study uses the longitudinal design in which data was collected by use of a validated questionnaire as the tool to collect data. Subjects are selected from students aged 12 to 13 in secondary schools.

A study on factors related to tobacco use among students in middle schools in China by Qing et al. ${ }^{10}$ shows that the prevalence of ever smoking is $19.7 \%$ in which $25.3 \%$ of them are male and $13.4 \%$ of them are female. This study also proves that peer pressure is one of the factors that have significant relationship with smoking behavior. This study includes 3.231 student aged 12 to 17 and subjects are randomly selected through a three-stage stratified cluster sampling in this study. Both the validated questionnaire and interview are used as the method for data collection in this study.

Another cross-sectional study on peer pressure and tobacco smoking among undergraduate students conducted by Ukwayi et al. ${ }^{11}$ shows $55.8 \%$ of respondents use tobacco daily, $20.8 \%$ occasionally use tobacco, $11.7 \%$ use once a week and $10.8 \%$ use tobacco 3 to 4 times in a week. This study shows that $46 \%$ of cigarette use among undergraduate students is caused by peer pressure. Subjects for this study are selected by purposive sampling. Hundred and twenty

Table 4 Cross-tabulation of Peer Pressure and Smoking Behavior

\begin{tabular}{|c|c|c|c|c|c|c|c|c|}
\hline \multirow{3}{*}{ Variable } & \multirow{3}{*}{$\begin{array}{c}\text { Alternative } \\
\text { answer }\end{array}$} & \multicolumn{4}{|c|}{ Smoking Behavior } & \multirow{2}{*}{\multicolumn{2}{|c|}{ Total }} & \multirow{3}{*}{ p-value } \\
\hline & & \multicolumn{2}{|c|}{ Ever smoked } & \multicolumn{2}{|c|}{ Never smoked } & & & \\
\hline & & $\mathbf{F}$ & $\%$ & $\mathbf{F}$ & $\%$ & $\mathbf{F}$ & $\%$ & \\
\hline \multirow{2}{*}{$\begin{array}{l}\text { Peer } \\
\text { pressure }\end{array}$} & Experienced & 56 & 81.2 & 13 & 18.8 & 69 & 100.0 & \multirow[t]{2}{*}{0.000} \\
\hline & $\begin{array}{l}\text { Never } \\
\text { experienced }\end{array}$ & 1 & 2.4 & 40 & 97.6 & 41 & 100.0 & \\
\hline Total & & 57 & 51.8 & 53 & 48.2 & 110 & 100.0 & \\
\hline
\end{tabular}


smoking students comprising of both female and male students who are selected through purposive sampling are included in the study. A validated questionnaire is used as a method for data collection.

There are several limitations and recommendations for this study. This study only includes peer factor as one of the factors that influence smoking behavior of adolescents. Other factors such as the parental factor and exposure to smoking related advertisement which have great influence on the smoking behavior of adolescents should be included in further studies for future intervention programs. Since the frequency of ever smoking students is high in elementary school students therefore intervention programs on prevention of tobacco use should be started at early age which can prevent the initiation of early adolescent smoking behavior.

In conclusion, there is a relationship between between peer pressure and smoking behavior in male elementary school students in Jatinangor district.

\section{References}

1. Heydari G, Yousefifard M, Hosseini $M$, Ramezankhani A, Masjedi MR. Cigarette smoking, knowledge, attitude and prediction of smoking between male students, teachers and clergymen in Tehran, Iran, 2009. Int J Prev Med. 2009;4(5):557-64.

2. Ellizabet AL. Stop merokok; sekarang atau tidak sama sekali. $1^{\text {st }}$ ed. Jogjakarta: Garailmu; 2010.

3. Adams ML, Jason LA, Pokorny S, Hunt Y. The relationship between school policies and youth tobacco use. J Sch Health. 2009;79(1):17-23.

4. U.S. Department of Health and Human Services. Preventing tobacco use among youth and young adults: a report of the surgeon general. Atlanta: Centers for Disease Control and Prevention, National Center for Chronic Disease Prevention and Health Promotion Office on Smoking and Health; 2012.

5. Simons-Morton BG, Farhat T. Recent findings on peer group influences on adolescent smoking. J Prim Prev. 2010;31(4):191-208.

6. Adebiyi AO, Faseru B, Sangowawa AO, Owoaje ET. Tobacco use amongst out of school adolescents in a Local Government Area in Nigeria. Subst Abuse Treat Prev Policy. 2010;5:24-8.

7. Huang H-L, Chen F-L, Hsu C-C, Yen Y-Y, Chen T, Huang C-M, et al. A multilevelbased study of school policy for tobacco control in relation to cigarette smoking among children in elementary schools: gender differences. Health Educ Res. 2010;25(3):451-63.

8. San San H, Myo O, Yoshida Y, Sakamoto J. Risk behaviours and associated factors among medical students and community youths in Myanmar. Nagoya J Med Sci. 2010;72(1-2):71-81.

9. Jeganathan PD, Hairi NN, Al Sadat N, Chinna K. Smoking stage relations to peer, school and parental factors among secondary school students in Kinta, Perak. Asian Pac J Cancer Prev. 2013;14(6):3483-9.

10. Qing Y, Termsirikulchai L, Vatanasomboon P, Sujirarat D, Tanasugarn C, Kengganpanich M. Factors related to tobacco use among middle school students in China. Southeast Asian J Trop Med Public Health. 2011;42(5):1249-61.

11. 11. Ukwayi JK, Eja OF, Unwanede CC. Peer pressure and tobacco smoking among undergraduate students of the University of Calabar.Cross River State. High Educ Stud. 2012;2(3):92-101. 